\title{
Problems of Additional Vocational Education
}

\author{
Albina Bilyalova \\ Kazan Federal University \\ Nabereznye Chelny, Russia \\ abil171@mail.ru
}

\author{
Azat Gaifutdinov \\ Naberezhnye Chelny State \\ Pedagogical University \\ Nabereznye Chelny, Russia \\ am-geo@mail.ru
}

\author{
Anifa Akhmetshina \\ Naberezhnye Chelny State \\ Pedagogical University \\ Nabereznye Chelny, Russia \\ anifa.k@gmail.com
}

\author{
Elina Tugusheva \\ Kazan Federal University \\ Nabereznye Chelny, Russia \\ e.tugusheva86@mail.ru
}

\begin{abstract}
The development of the system of additional vocational education as an integral part of lifelearning education is very important for Russia because today it is the key to personal competitiveness of both the employee and the organization in the labor market, since the qualification of employees is directly depend on the competitiveness of the company. The article presents modern view to the system of additional vocational education. The authors reveal the basic concepts of a subject, the main principles of the development of additional vocational education, factors that influence its organization, tendencies of its development, and the problems of the functioning of additional vocational education.
\end{abstract}

Keywords additional vocational education, lifelong learning, labor market, competitiveness.

\section{INTRODUCTION}

In the modern world, Education is one of the basic categories of development of both the individual and society as a whole. By the middle of the twentieth century, there was a steady trend of increasing professional and specialized knowledge, and by the end of the twentieth century, the widespread theory of the information society led to the need to revise the system of traditional Education, including vocational Education. Already in the early 1970s, lifelong education was considered by UNESCO as the main principle of educational policies for the future.

In the second half of the XX century in the Soviet Union the system of institutes of advanced training of specialists and managers in various branches of the national economy begins to develop. By the nineties, the need for additional vocational education in connection with the changed economic conditions has become more than relevant. Currently, the principle of lifelong Education is a priority in the reform of Education in all countries. Theoretical and practical searches for models of lifelong Education that meet the needs of the new century of "humanitarian thinking" (D.S. Likhachev) are actively pursued in the last several decades both internationally and nationally, and the attempts are being made to implement them in order to build the system of lifelong Education.

In Russian Educational Reform the idea of lifelong Education is the basic principle of all educational initiatives. In modern Russian society, the implementation of life-long principle takes place primarily in two directions. Firstly, within the framework of postgraduate education, which includes advanced training, postgraduate study, doctoral studies, scientific training, during which the specialist increases his professional skills acquired in the process of obtaining basic education. Secondly, the instrument for the implementation of the concept of lifelong education is the institution of additional vocational education which is currently being developed. Its tasks include: obtaining a second higher education; professional retraining, during which the specialist can change his profession or receive additional qualifications within the framework of the vocational education already obtained; receiving a variety of educational services in a professional sphere.

Additional vocational education today is the key to personal competitiveness of both the employee and the organization in the labor market, since the qualification of employees is directly depend on the competitiveness of the company.

So, additional vocational education is a life-long education system that includes the set of interacting successive educational programs and state educational standards, state requirements for minimum content and for level of training of students on individual additional professional programs and learning areas.

In general, the system of additional vocational education is focused on a close connection with changes in the real sector of the economy and with the satisfaction of the needs of the individual of society and the state in life-long education. The main reasons for the changes in the labor market are social and economic reforms, and therefore the professional mobility of the employee and his personal qualities play a decisive role. For this reason, there is a reform of education towards the establishment of a humanistic paradigm. The most valuable in this reform is the person's personality, his ability to develop not only professional, but also intellectual and moral qualities 
in order to enhance his ability to adapt in the ever-changing structure of the labor market.

At the present stage of education development, the main attention of researchers and experts is paid to trends which have an crucial impact on the development of the global education system $[4 ; 6 ; 8 ; 10 ; 15 ; 17]$.

Population ageing, globalization, rapid change of technological platforms-all this has a significant influence on the "educational landscape" [5]. The world of professions is becoming more complicated; their typology in a number of areas of activity is becoming much wider. In the conditions of technological progress, constant updating of the information array there is a need for constant improvement and development of knowledge and experience accumulated by specialists. Being a student, studying the intricacies of one profession or another without being sure that the relevant narrowly specialized qualification will be in demand at labor market, is becoming an unaffordable luxury. Changes in the economy and society, demographic trends indicate the relevance of the transition to a model of lifelong education $[7 ; 8 ; 13]$.

These needs are provided by additional vocational education (AVE), which has become a factor in the sustainable socio-economic development of the region and the country as a whole, more over it contributes to the adaptation of employees to continuous changes in various spheres of society.

Many experts studying the modern labor market report that currently specialists of a narrow profile have become much less in demand than a few years ago $[12,18,19]$. Such specialists even lose their jobs, and in their place employers invite universal employees. Thereby, additional training increases the market demand for representatives of any and all professions. That is why the most rational and preferred option will be a deep specialization in a particular field and mastering an additional specialty in related fields.

Thus, additional vocational education provides lifelong creative development, updating knowledge, improving skills, and also contributes to the development of soft skills such as the ability to be flexible, make decisions, be adaptive to changes in professional activity, and to develop continuously [11].

The University is one of the main and significant stages in the chain of lifelong education. Additional vocational education in the conditions of higher education gives the employee the opportunity not only to upgrade their qualifications, but also to undergo professional retraining and acquire knowledge and skills that will allow them to work in a different field of activity. The importance of the development of the system of additional vocational education in the Russian Federation is difficult to overestimate. The system of additional higher education with the assignment of additional qualifications significantly increases the dynamics of the response of higher education on the changing needs of the labor market in highly qualified specialists, as it allows not only working professionals, but also students and graduate students during the period of training in basic educational programs to master the relevant additional educational programs.

Additional vocational education is today a pledge both of the personal competitiveness of the employee in the labor market and of the organization, since the qualifications of employees are directly related to the competitiveness of the company. The urgency of the work is due to the above.

\section{Methodology}

The paper is devoted to the analysis of additional vocational education as a system focused on a close relationship with changes in the real sector of the economy, and the state and directions of the development of the system of additional vocational education in Russia is also examined.

This article explores the problems of AVE, ways of its realization in the structures providing improvement of professional skill and professional retraining of the employee according to requirements of modernization of an education system; and also in this article the urgent need for additional vocational education for increasing the level of competitiveness in the labor market is underlined. The main problems of the implementation of additional vocational education, as well as modern trends in the development of additional professional education are investigated.

The theoretical and methodological basis of the study are the papers of such researchers as M.Burns, T.Caswell, S.Henson, M.Jensen, D.Wiley [2;3;9;14].

The analysis of theoretical and supporting data comprise the usage of such methods: system analysis; structural functional, and institutional approaches to the study of the object and the subject; the development of a conceptual apparatus; the construction of hypotheses; comparison and generalization in the analysis of the results.

\section{RESULTS AND DISCUSSION}

Analyzing the system of additional vocational education, it is necessary to consider the basic concepts in this field. According to the definition of the Federal law "On Education", additional education is a type of education that is aimed at fully meeting the educational needs of a person in intellectual, spiritual, moral, physical and (or) professional development and is accompanied by development of soft skills. Thus, additional education is a type of education aimed at improving the person's skills and meeting his needs.

Speaking about the system of additional vocational education, it is important to state the difference between traditional and additional Education. Additional vocational education is characterized by high mobility and short-term educational process that allows to quickly respond to fluctuations in the labor market; the ability to more flexible meeting the needs of the labor market specialists in the number, profile and level of training. Additional vocational education includes a wider range of educational and related services, i.e. training in rare professions; rapid organization and training teams of specialists for a specific order; prompt response to requests from enterprises and training of 
specialists for specific jobs. These features favorably distinguish the AVE system from the traditional general professional education.

It is legally determined that the programs of additional vocational education have division into two categories: programs of advanced training and programs of professional retraining. The program of advanced training is aimed at obtaining new competencies or improving existing skills required to carry out professional activities or professional development in relevant vocation. Professional retraining programs involve the development of new professional activities, obtaining competencies for the acquisition of new skills.

Additional vocational training programs also vary in length and form. They can be implemented in the form of mentoring, trainings and seminars, short-term training courses less than 1 month and duration of 1 to 3 months, long-term programs from 6 months to 1 year, retraining programs for more than a year, internships, MBA programs.

The main principles of the development of additional vocational education are: uninterrupted nature of additional vocational education, including engineering education; the unity of business management and educational process; ensuring the unity of vocational training and upbringing; taking into account the interests of the individual, society and the state; integration of educational structures and programs ensuring continuity of professional education; individualization of additional vocational education, providing for personal orientation.

The organization of the additional vocational education system is strongly influenced by the following groups of factors:

- both global and national factors, which are specified by culture of countries, nations, and culture of the whole world;

- regional factors, arising under the influence of the cultural characteristics of a particular region;

- local factors, reflecting the local characteristics and traditions of ethnic culture and education.

It should be noted that the Russian education system differs from the foreign education system with less variability. However, the additional vocational education system developed in Russia is more variable than the whole Russian vocational system of education, which is provided by its focus on the comprehensive satisfaction of the educational needs of citizens, society and the state.

The main objectives of additional vocational education are:

- professional development of employees based on the current level of employers ' requirements;

- meeting the needs of the employer for further training and retraining;

- development and stimulation of needs for professional development and retraining of personnel;

- ensuring social security, social rehabilitation and employment of specialists, etc.

In the field of additional vocational education it is possible to allocate the following tendencies, which, as a whole, are consonant with the world universal requirements for training specialists.

First, modern society is characterized by rapid obsolescence of information, which results in the devaluation of specialized professional knowledge, which in turn creates the need for the resumption of vocational education. The average rate of time for updating applied, and in many ways basic, professional knowledge in technologically advanced industries is 3-5 years, during which up to a third of the employee's special knowledge is depreciated. Thus, during the period of active work, a person has to resume his / her vocational education three or four times, which leads to the demand for further and lifelong education. This trend is most evident in the concept of lifelong learning.

Secondly, currently among the means of production, wage labor and information (knowledge) are the most expensive. Changes in the structure of the economy, the active development of small and medium-sized businesses have made it necessary to combine several functions in one person (for example, manager and technologist, manager and accountant, etc.). Therefore, in the modern world, in which the external environment is changing quite rapidly, for a specialist, you must either have a sufficiently diverse training (which, in principle, was a characteristic feature of the Soviet (Russian) higher school based on basic training of specialists with higher education), or there should be an orientation to the training of a universal specialist, that is, an individual who masters several specialties. It should be noted that the paradigm of a narrow specialist in the education system is gradually replaced by the paradigm of a professional focused not so much on the implementation of job descriptions, but on achieving specific goals through the use of a wide arsenal of methodological and instrumental tools [16].

The third trend is connected first of all with the problem of non-demand in the labor market of certain specialists, including those who have graduated from universities. In this case, such a criterion as readiness and the capacity for further professional training begins to play a special role for the employer.

The fourth trend is the following. The largest number of students in the AVE system belong to health care, education, oil and gas, energy, heavy industry, as well as the financial sector. On the contrary, the least trained people work in light manufacturing, textile and food industry, agriculture. In addition, there are some differences in the distribution of students depending on the form of ownership of employers: in state enterprises their number is more than in private enterprises; among the latter, professional retraining is the prerogative of enterprises of mostly foreign owners (which occupy a very small share in the total number of organizations).

The above-mentioned trends suggest increasing the importance of AVE in modern society, since the system of additional education occupies a specific position: on the one hand, educational services are focused on getting the individual the necessary professional knowledge in a short time on certain conditions; on the other hand, educational 
programs are organized with taking into account the needs of the labor market.

So, the analysis allows us to state that in the conditions of the fundamental changes in the socioeconomic structure of the country and in the public consciousness, the role of additional vocational education is growing. There is an urgent need for universities that must meet the ever-changing social, cultural and educational needs and to create conditions for the creative self-realization of a person [1].

Further, we consider it important to outline some of the problems that have been identified in the theoretical analysis of studies by Russian and foreign scientists. The problems are mainly related to the organization of AVE and have both pedagogical and legislative character.

The difference between the educational process in system of additional vocational education from its traditional program in the university is explained, first of all, by the heterogeneity of the contingent, and also by the different nature of the teacher-student interaction. Short terms of preparation, a great interest in gaining professional knowledge, the prevalence of practical knowledge over theoretical, more intensive educational technologies, a greater variety of the forms of training used require the joint active work of both the teacher and the student. Therefore, personnel issues of the AVE system, development of scientific and educational materials in the field of new pedagogical technologies are the key points.

The problem of the legal basis for the functioning of the AVE system is acute. Currently additional vocational education functions within the scope of the Federal Law "On Education" and "On Higher and Postgraduate Professional Education", but these laws can not fully provide legal regulation of activities on a number of issues, for example, related to the quality management of AVE, including issues of educational standards and state requirements to the minimum content of educational programs and the level of skill requirements for specialists, also to licensing, certification and accreditation of educational institutes and the educational programs of the AVE, the development of the legal framework for the integrated assessment procedure (relicensing, certification, state accreditation). Thus, today there is an urgent need to create an adequate legal framework for the functioning of the AVE system. And this problem is one of the most important ones.

Modernization of education is currently the leading idea of the whole world educational policy and the most discussed problem, but, despite the abundance of various programs and reports, there is still no experience of systematic understanding of the reform as a socio-cultural phenomenon, included in different contexts and producing very different. And it is one more serious problem in the sphere of additional vocational education.

\section{CONCLUSIONS}

Additional professional education is an integral part of becoming a specialist, as an individual, as a professional, as a competitive subject in the labor market.
Considering the development of the institution of additional vocational education as part of the concept of lifelong education, as a means of constantly enriching the individual's creative potential, we believe that professional mastery is achievable on the condition of continuous general and professional education and personal development in the system of basic and additional vocational education and is not limited only by acquiring narrow professional skills.

The development of a system of life-long professional education is based on the introduction of industry in the sphere of basic training and on the penetration of training in industry process. Thus, there is a blurring of the boundaries between the stages of the educational process, and of the boundaries between basic training and professional experience. At the same time, in the conditions of technological progress, constant updating of the information, there is a need for constant improvement and development of knowledge and experience accumulated by specialists. These needs are provided by additional vocational education, which becomes a factor of sustainable socio-economic development of the region and the country as a whole, contributes to the adaptation of workers to continuous changes in various spheres of society. It is the main link between the interests of the individual, society and the state, between different levels of vocational education and economic sectors, the demands of employers and the requests of direct consumers of educational services.

The main principles the development of additional vocational education are:

the continuous nature of additional vocational education (life-long education);

cooperation of business management and educational process;

ensuring the unity of vocational education and upbringing; taking into account the interests of the individual, society and the state;

integration of educational structures and programs, ensuring the continuity of vocational education;

individualization of additional vocational education.

The system of additional vocational education is the basis for the introduction of new technologies in the educational process. The tendency to "accelerate" learning, the individualization of the process, the projectivity of education make it necessary to combine educational forms, to seek new technologies.

Summing up, it can be concluded that further development of the system of additional vocational education is aimed at the solution of the following priority tasks:

- organization of real demand for educational services at the system of additional vocational education;

- using effective ways to increase motivation in professional development and professional retraining of specialists;

- the level of the additional vocational education system should be improved adequately with the demand for educational services; 
- creation of vocational guidance centers for the population;

- preparation of highly qualified teaching staff of additional vocational education and their regular training;

- creation and adaptation of information, technical and educational-methodological base for the additional vocational education system, which allows to quickly design educational programs, provide high quality of training that meets the expectations of customers and the requirements of state educational standards.

As for the solution of the problem of the additional vocational education at the state level, it should be noted that the priority areas of activity are the interaction of the administrative departments with the educational institutions, as well as the creation and improvement of the legal framework that guarantees the receipt of high quality educational services.

Finally the following conclusions can be drawn:

- the goals of the additional vocational education system are aimed at meeting the interests and needs of citizens, business and the state as a whole. Only by guaranteeing the realization of citizens rights to lifelong learning we can count on the development of the business community and the stable development of the national economy;

- there are global trends in the development of the system of additional vocational education, conditioned by the following factors: 1) the labor market is an indicator for the creation of new directions and specialties of additional vocational training; 2) the change in the period of obsolescence of knowledge requires lifelong professional training; 3) when training a specialist, the tendency of narrow specialization to the trend of professional competence in a wide range of issues is changing; 4) the labor market is an indicator for the creation of new directions and specialties of additional vocational training.

the peculiarity of the organization of the educational process in the system of additional vocational education demands the use of innovative teaching and methodological developments and pedagogical technologies by teaching staff and requires constant improvement and enhancement of teaching competence.

- $\quad$ there is an urgent need to establish an adequate legal framework for the functioning of the AVE system, because existing Federal laws "On education" and "On Higher and Postgraduate Vocational Education" cannot fully ensure the implementation of the objectives of the AVE. It leads to the need for further improvement of the legislation.

\section{REFERENCES}

[1] Bilyalova, A. (2017). ICT in Teaching a Foreign Language in High School // Procedia - Social and Behavioral Sciences 237 ( 2017 ) 175 - 181.

[2] Burns, M. (2011). Distance Education for Teacher Training: Modes, Models and Methods. Retrieved September 3, 2013, from http://www.idd.edc.org/resources/publications/modes-models-and-methods [3] Caswell, T., Henson, S., Jensen, M., \& Wiley, D. (February 2008). Open educational resources: Enabling universal education. International Review of Research in Open and Distance Learning 9(1).
[4] Cervero, R.M. (2000) Trends and issues in continuing professional education. In V.W.Mott \&B.D.Daily (Eds.), Charting a course for continuing professional education: Reframing professional practice. New directions for Adult and Continuing Education, № 86. San Francisco: Jossey Bass.

[5] Cervero, R.M.(2001) Continuing professional education in transition, 1981-2000. International Journal in Lifelong Education, 20(1), 16-30.

[6] Daley, B.D.., Mot, V.W. (2000). The future of continuing professional education: From vision to reality. In V.W.Mott \&B.D.Daily (Eds.) Charting a course for continuing professional education: Reframing professional practice. New directions for Adult and Continuing Education, № 86. San Francisco: Jossey Bass.

[7] Dave R. N. Foundation of Lifelong Education: Some Methodological Aspects. - Hamburg, 1976. - P. 34.

[8] Dillemans, R., Lowyck, J., Van der Perre, G., Claeys, C., \& Elen, J. (1998). New technologies for learning: Contribution of ICT to innovation of education. Leuven, Belgium: Leuven University Press.

[9] Peter Hernon, Robert E. Dugan, Candy Schwartz. Higher education outcomes assessment for the twenty-first century. Libraries Unlimited: an Imprint of ABC-CLIO, LLC, 2013. $257 \mathrm{p}$.

[10] Leo Goedegebuure, Frans Kaiser, Peter Maassen, Lynn Meek, Fras van Vught and Egbert de Weert. Higher education policy. An international comparative perspective. Pergamon Press, 2013.362 p.

[11] Mabry, C.K. (2000). Negotiating Power and Interests in Program Planning for Adult Education: Multiple Interviews with Adult Educators at a Large, Multi-national Cooperation. (Doctoral Dissertation, North Carolina State University, 2000). Dissertation Abstract International, 61 (03), 850

[12] Rapkins, C. (1996). Best Practice for Continuing Professional Development: Professional Bodies Facing the Challenge in I. Woodward (ed.) Continuing Professional Development-Issues in Design and Delivery. London: Cassell.

[13] Recommendation of the European Parliament and of the Council on the establishment of the European Qualifications Framework for lifelong learning // Official Journal of the European Union. 2008.

[14] Schunk D. Learning theories: an educational perspective (third edition). Oakland, New Jersey: Merrill, 2002.

[15] Senior, C. (1999). Lifelong learning and Continuing Professional Development. Gower Handbook of Training and Development. Hampshire: Gower Publishing

[16] Sobiechowska P. \& Maisch, M. (2007). Work-based Learning and Continuing Professional Development, Education and Training, 49(3): pp, 182-192

[17] Trends Shaping Education. Centre for Educational Research and Innovation. 18 Jan 2016. Retrieved from: http://www.oecdilibrary.org/education/trends-shaping-education-2016_trends_edu-2016-en (assessed date: 09.02.2016).

[18] Van Loo, J. B. \& Rocco, T. S. (2006). Differentiating CPE from Training: Reconsidering Terms, Boundaries and Economic Factors. Human Resource Development Review, 5(2): 202-227

[19] Queeny, D.S. (2000). Continuing professional education. In A.L.Wilson and E.R.Haeys (Eds.), Handbook of adult and Continuing Education 2000 (pp. 375-391). 